\title{
The buried stent: a rare complication of endoscopic ultrasound-guided pancreatic necrosectomy using a lumen-apposing metal stent
}

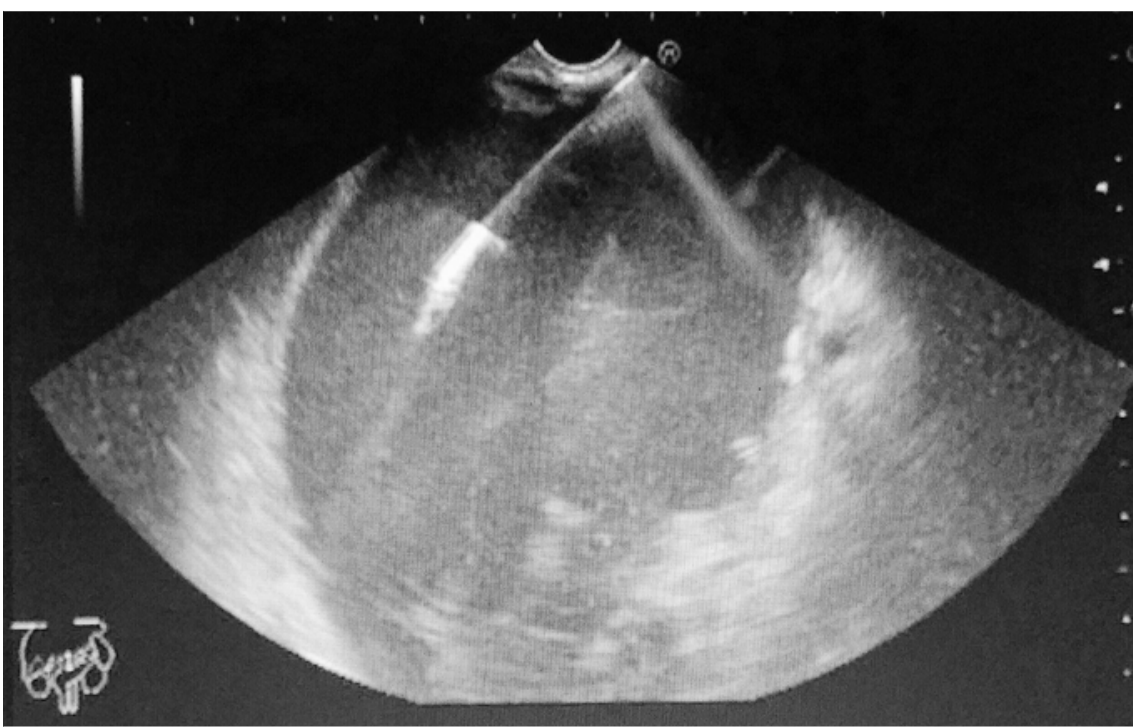

Fig. 1 Endoscopic ultrasound-guided drainage of walled-off pancreatic necrosis in a 51-year-old man: a large, thick-walled pancreatic fluid collection about $15 \times 13 \mathrm{~cm}$ in size with necrotic debris was punctured with a 19-gauge needle.
A 51-year-old man was referred to our facility for endoscopic ultrasound-guided drainage of walled-off pancreatic necrosis. The cyst was first punctured with a 19-gauge needle ( $\mathbf{F i g} \cdot \mathbf{1})$. A NAGI stent (Taewoong Medical, Seoul, South Korea) was then deployed under ultrasonographic and fluoroscopic guidance without difficulty ( $\triangleright$ Fig. 2, $\triangleright$ Video 1). A computed tomography (CT) scan 6 weeks later revealed significant reduction in the cyst size with residual necrotic debris. Upper endoscopy showed an orifice in the middle of a small bulge of gastric mucosa and the stent could not be seen. The cystogastrostomy tract was cannulated and dilated with a 15-mm pneumatic balloon ( $\triangleright$ Fig.3). The extremity of the lumen-apposing metal stent (LAMS) embedded in the gastric wall was identified, and the stent was removed using rat-tooth forceps ( $>$ Fig. 4 ). The endoscope was then passed into the cyst cavity and the residual necrotic debris was irrigated and removed with a snare. A follow-up CT scan after 3 months revealed an almost totally collapsed cyst cavity, consistent with drainage of the collection.

Plastic stents were conventionally used for the drainage of pancreatic fluid collections, and although their pigtail feature decreases the risk of migration, premature occlusion usually occurs [1].

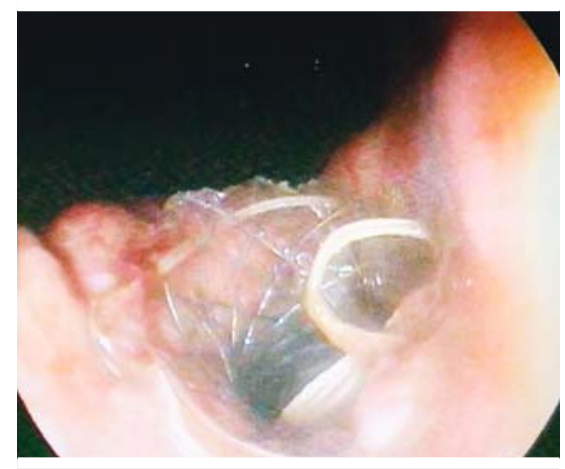

Fig. 2 Endoscopic ultrasound-guided pancreatic necrosectomy: NAGI stent after successful deployment.

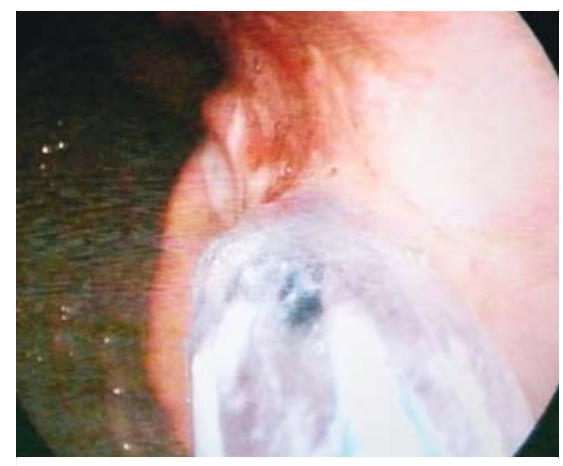

- Fig. 3 The lumen-apposing metal stent cannot be seen. The cystogastrostomy tract is cannulated and dilated with a 15-mm pneumatic balloon. 


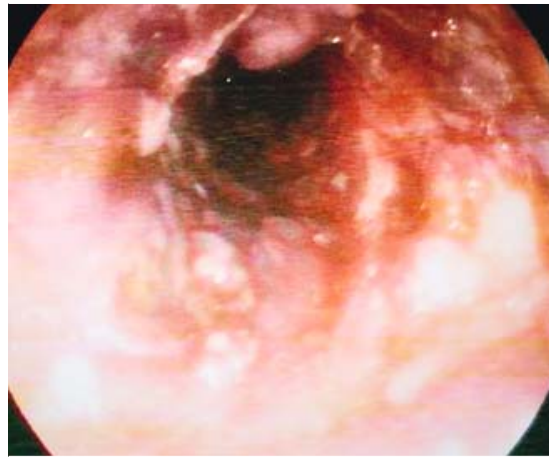

- Fig. 4 Cystogastrostomy tract after removal of the stent with rat-tooth forceps.

Metal stents provide larger diameter lumens for better drainage, but their tubular feature increases the risk of migration [2]. The LAMS attempts to overcome these technical challenges with a "dumbbell" configuration to avoid stent migration and a large diameter allowing necrosectomy in repeated sessions [3]. Fabbri et al. were the first to describe a rare adverse event for the use of the LAMS that resembled the "buried bumper" associated with complicated percutaneous endoscopic gastrostomy, which they called the "buried stent" [4]. The buried stent appears to be a potential problem associated with use of the LAMS. To the best of our knowledge, this is the second reported case of a buried stent and the first reported case of endoscopic ultrasound-guided pancreatic necrosectomy in Egypt.

\section{Endoscopy_UCTN_Code_TTT_1AS_2AD}

\section{Competing interests}

None

The Authors

\section{Ahmed Y. Altonbary, Hazem Hakim}

Department of Gastroenterology and Hepatology, Mansoura Specialized Medical Hospital, Mansoura, Egypt

\section{Corresponding author}

\section{Ahmed Y. Altonbary, MD}

Department of Gastroenterology and Hepatology, Mansoura Specialized Medical Hospital, Mansoura 35516, Egypt

a.tonbary@gmail.com

\section{References}

[1] Singhal S, Rotman SR, Gaidhane M et al. Pancreatic fluid collection drainage by endoscopic ultrasound: an update. Clin Endosc 2013; 46: $506-514$

[2] Walter D, Vleggaar F, Siersema P. Self-expandable metal stents for endoscopic ultrasound-guided drainage of peripancreatic fluid collections. Gastrointest Interv 2013; 2: $24-29$

[3] Yamamoto N, Isayama H, Kawakami $\mathrm{H}$ et al. Preliminary report on a new, fully covered, metal stent designed for the treatment of pancreatic fluid collections. Gastrointest Endosc 2013; 77: 809-814

[4] Fabbri C, Luigiano C, Marsico M et al. A rare adverse event resulting from the use of a lumen apposing metal stent for drainage of a pancreatic fluid collection: "the buried stent”. Gastrointest Endosc 2015; 83: 585 587

Bibliography

DOI http://dx.doi.org/10.1055/s-0042-124505

Endoscopy 2017; 49: E84-E85

(c) Georg Thieme Verlag KG

Stuttgart · New York

ISSN 0013-726X 